\title{
Thank You for Smoking
}

I hope readers get a chance to see Thank You for Smoking, a recently released film adapted from Christopher Buckley's book of the same name. In the film, a Tobacco Institute lobbyist uses his charm, good looks, and a careful turn of phrase to combat the terribly flawed data that relates cigarette smoke to cancer and other diseases. Smoking, of course, is about freedom and the courage to make a choice. And if you noticed the tongue in my cheek in the statements above, you may also suspect that several turns and twists in the film make his world more complicated than he expected.

I recognized the satire, but didn't notice one fascinating element until I heard the crowd murmuring while walking out of the theater: no one in the movie smoked. This lack of smoking in a film whose (anti)hero defends smoking projects a powerful message from an amoral construct: smoking is no longer socially acceptable, at least not among the demographic this movie targets.

And statistics suggest that the message is getting out. This year witnessed a decrease in the incidence of lung cancer in men and women and a decrease in mortality for men. ${ }^{1}$ Fewer people are starting to smoke, and more people are quitting. Not all the news is good, however. Too many young people still take up this habit, and the prevalence of smoking outside the United States is alarming. A quick search shows that $20 \%$ of male Chinese medical students smoke. ${ }^{2}$

I was interested, therefore, to see the report by Lin et al. in this issue on the effect of a hospital ban on smoking on current cigarette use and attitudes about the regulations among employees. The City of Hope banned smoking anywhere on the 100-acre campus in 1989. Although the numbers are small, data suggest that smokers used fewer cigarettes during workdays than on weekends. Further, $42 \%$ quit smoking while employed there. Finally, $93 \%$ of the respondents supported the ban.

Sure, this hospital (an NCCN member institution) is in California, a state leading the nation in smoking legislation and a state that already has one of the lowest smoking rates in the country. ${ }^{3}$ However, workplace bans have had similar effects in other U.S. areas. ${ }^{4}$ In other words, ugly things such as regulation and taxes do reduce smoking, improve health, and help those adversely affected by second-hand smoke.

This is my first editorial sharing the role with Dr. Winn. Most of my writing will not be this heavy-handed, but I find it difficult to separate public health from the personal effects of smoking. While I was in grade school, lung cancer killed my 66-year-old grandfather. I've watched my mother exchange a very active life for a tank and a nasal cannula. Less than 1 year after my mother-in-law asked me to look at a chest x-ray for her, I attended her funeral. And last fall, I found 8 cans of Skoal in my son's dresser drawer. And that doesn't include the patients and families I've seen damaged along the way.

I enjoyed the film's satire, full of spin-doctors and "merchants of death," and I applaud the public health efforts that have made significant strides in this country. However, we still have a lot of work to do to discourage our young people from starting to smoke and to help our established patients stop. 
July 2006

\section{References}

1. Jemal A, Siegal R, Ward E. Cancer statistics, 2006. CA Cancer J Clin 2006;56:106-130.

2. Lei Z, Jingheng H, Jianzhong L. Smoking among Shanghai medical students and the need for comprehensive intervention strategies. Health Promot Int 1997;12:27-32.

3. Jiles R, Hughes E, Murphy W, et al. Surveillance for certain health behaviors among states and selected local areas: behavioral risk factor surveillance system, United States, 2003. Morbid Mortal Wkly Rep 2005;54(SS08):1-116.

4. Evans WN, Farrelly MC, Montgomery EB. "Do Workplace Smoking Bans Reduce Smoking?" Washington, DC: National Bureau of Economic Research; 1996: Working Paper W5567. 